\title{
Fractured Geothermal Growth Induced by Heat Extraction
}

\section{J.W. Tester}

Massachusetts Inst. of Technology

H.D. Murphy

C.0. Grigsby

R.M. Potter

B.A. Robinson

Los Alamos Natl. Laboratory

entogh

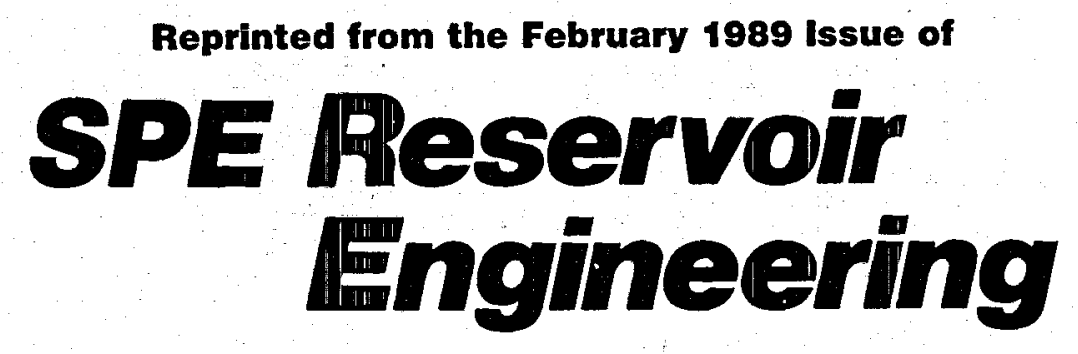




\section{DISCLAIMER}

This report was prepared as an account of work sponsored by an agency of the United States Government. Neither the United States Government nor any agency Thereof, nor any of their employees, makes any warranty, express or implied, or assumes any legal liability or responsibility for the accuracy, completeness, or usefulness of any information, apparatus, product, or process disclosed, or represents that its use would not infringe privately owned rights. Reference herein to any specific commercial product, process, or service by trade name, trademark, manufacturer, or otherwise does not necessarily constitute or imply its endorsement, recommendation, or favoring by the United States Government or any agency thereof. The views and opinions of authors expressed herein do not necessarily state or reflect those of the United States Government or any agency thereof. 


\section{DISCLAIMER}

Portions of this document may be illegible in electronic image products. Images are produced from the best available original document. 


\title{
Fractured Geothermal Reservoir Growth Induced by Heat Extraction
}

\author{
J.W. Tester, SPE, Massachusetts Inst. of Technology, and H.D. Murphy, SPE, C.o. Grigsby, \\ R.M. Potter," SPE, and B.A. Robinson, Los Alamos Natl. Laboratory
}

\begin{abstract}
Summary. Field testing of a hydraulically stimulated, hot, dry rock (HDR) geothermal system at the Fenton Hill site in northern New Mexico indicated that significant reservoir growth occurred as energy was extracted. Tracer, microseismic, and geochemical measurements provided the primary quantitative evidence for the increases in accessible reservoir volume and fractured rock surface area that were observed during energy extraction operations that caused substantial thermal drawdown in portions of the reservoir. These temporal increases suggest that augmentation of reservoir heat-production capacity in an HDR system may be possible.
\end{abstract}

\section{Background}

Commercial exploitation of HDR in low-permeability formations requires access to large rock surface areas and volumes. The concept consists of creating a labyrinth of flow paths with recirculated water to remove a portion of the thermal energy contained in the hot rock mass at depth. This process of heat mining has been achieved in a prototype field reservoir located in the Jemez Mountains of northern New Mexico. At the Fenton Hill site, average geothermal gradients of $55^{\circ} \mathrm{C} / \mathrm{km}^{\prime}\left[0.03^{\circ} \mathrm{F} / \mathrm{ft}\right]$ are found in crystalline granitic rock with microdarcy to nanodarcy permeability. The active reservoir discussed in this paper was created by hydraulic fracturing over a depth interval from about 2.7 to $2.9 \mathrm{~km}[8,800$ to 9,500 $\mathrm{ft}$, where initial rock temperatures from 170 to $200^{\circ} \mathrm{C}$ [338 to $\left.392^{\circ} \mathrm{F}\right]$ are found. The main section of the fracture system is located in a body of biotite granodiorite consisting primarily of four major minerals: potassium feldspar (19\%), plagioclase feldspar (36\%), quartz (26\%), and biotite (12\%). The granodiorite section is texturally equigranular and nonfoliated with frequent sealed joints or natural fractures. Earlier publications describe the geologic setting and reservoir characteristics in detail. ${ }^{1-3}$

\section{Summary of Fleld Testing}

A small reservoir was initially created by hydraulically fracturing Well EE-1 and sidetracking from Well GT-2 to pass through the fractured region. At depths of 2.5 to $2.9 \mathrm{~km}[8,200$ to $9,500 \mathrm{ft}$, the minimum principal earth stress is horizontal, suggesting that induced or activated fractures would favor a vertical structure, possibly along weakly cemented joints or those joints favorably aligned in relation to the minimum-stress direction. Testing of this system was conducted during Segments 2 and 3 of the Los Alamos program during 1979. Details are presented in a number of Los Alamos reports summarized by Armstead and Tester. 4

Later in 1979, a larger system was created by fracturing from Well EE-1 after recementing the injection zone of the original reservoir at about $2.75 \mathrm{~km}[9,000 \mathrm{ft}]$. The injection region of the enlarged system was drilled to $2,93 \mathrm{~km}[9,600 \mathrm{ft}]$, increasing the separation distance between the production zones in the sidetracked Well GT-2B and the injection zone in Well EE-1 from about 100 to $300 \mathrm{~m}$ [330 to $980 \mathrm{ft}$ ]. Testing of the enlarged system was carried out in Segments 4 and 5 from 1979 through 1981.

The systems were operated in a heat extraction mode during the Segments 2 through 5 , with fluid injected under approximately constant injection and production pressure conditions of about 8.5 and 1.1 $\mathrm{MPa}$ [1,200 and $160 \mathrm{psi}]$, respectively. Heat was removed from the recirculated fluid at the surface with air-cooled, finned-tube heat exchangers. Makeup water was added as required to replace fluids permeating into the formation surrounding the pressurized active reservoir. Total thermal-energy-removal rates were calculated with measured downhole Production Well GT-2B temperatures at 2590 $m[8,500 \mathrm{ft}]$ and a constant $25^{\circ} \mathrm{C}\left[77^{\circ} \mathrm{F}\right]$ reinjection temperature at the surface. Energy-removal rates within the reservoir were based on estimated downwell injection temperatures obtained from a calibrated wellbore heat-transmission model.

- Now rettred.

Copyright 1989 Society of Petroleum Engineers
Average thermal-energy-removal rates for the test were $3.1 \mathrm{MW}$ thermal (MWt) for Segment 1, 2.1 MWt for Segment 2, 2.8 MWt for Segment 4, and 2.3 MWt for Segment 5. After 75 days of operation in Segment 2, the fluid temperature had dropped from 175 to $85^{\circ} \mathrm{C}$ [347 to $185^{\circ} \mathrm{F}$ ]. Twenty-three more days of production during Segment 3 showed a range of 135 to $98.5^{\circ} \mathrm{C}$ [275 to $209^{\circ} \mathrm{F}$, whereas temperatures during the 24-day Segment 4 test of the enlarged reservoir remained constant at $153^{\circ} \mathrm{C}\left[307^{\circ} \mathrm{F}\right]$. During extensive testing in Segment 5, production temperatures increased from 156 to about $158^{\circ} \mathrm{C}\left[312\right.$ to $\left.316^{\circ} \mathrm{F}\right]$ after 60 days and then decreased to about $149^{\circ} \mathrm{C}\left[300^{\circ} \mathrm{F}\right]$ after 286 days of operation.

In addition to these energy-extraction tests, a unique experiment was conducted at the end of Segment 5 to release excessive reservoir stresses resulting from heat removal. This experiment is referred to as the stress-unlocking experiment (SUE) (see Refs. 4 and 5 for details). The SUE test was carried out after 278 days of energy extraction in Segment 5 , when about $15 \times 10^{6} \mathrm{~kW} \cdot \mathrm{h}\left[51 \times 10^{9} \mathrm{Btu}\right]$ of thermal energy had been extracted from the reservoir. Relaxation of thermal stresses was accomplished by pumping water into Well EE-1 at pressures of about $15 \mathrm{MPa}[2,200$ psi] with Production Well GT-2B shut in. With these higher injection pressures, the normal and frictional stresses holding the fracture faces together during the energy-extraction tests would be exceeded, resulting in shear slippage and microseismicity that could be monitored. Reservoir diagnostic tests were conducted before and after SUE to characterize any change in reservoir geometry.

\section{Dlagnostlc Test Methods}

Thermal Hydraulic Techniques and Models. During all testing, surface and downhole temperature and flow measureménts were made. A spinner/temperature logging tool was used for all downhole measurements. During extended production periods, the spinner/ temperature tool was positioned in Production Well GT-2B inside the casing above all production zones. Periodically, logging was accomplished during production with a pressurized cable packoff system mounted in Production Well GT-2B wellhead.

One model used to estimate the effective heat-transfer area assumes one-dimensional (ID) or two-dimensional (2D) steady flow in a planar fracture coupled to ID conduction in the rock perpendicular to the flow field. Thus, the rate of production temperature decline or thermal drawdown will be controlled by the areal, rather than volumetric, features of the rock exposed to the circulating fluid. Although simplistic, this areal-sweep model conveniently describes the thermal behavior of a fractured reservoir by matching the observed thermal drawdown with a single adjustable parameter, the fracture area. This fitted area should be regarded as an effective heat-transfer area for modeling purposes only.

Large-scale heterogeneities, such as the superposition of flows in multiple joints, undoubtedly exert great influence on heat-transfer behavior because the spatial positioning of these low-impedance conduits effectively defines the accessible volume of rock. In the two HDR systems studied to date, the onset and subsequent rates of thermal drawdown seem to be controlled by that portion of the reservoir surface area of the flow paths directly connecting the wells. 

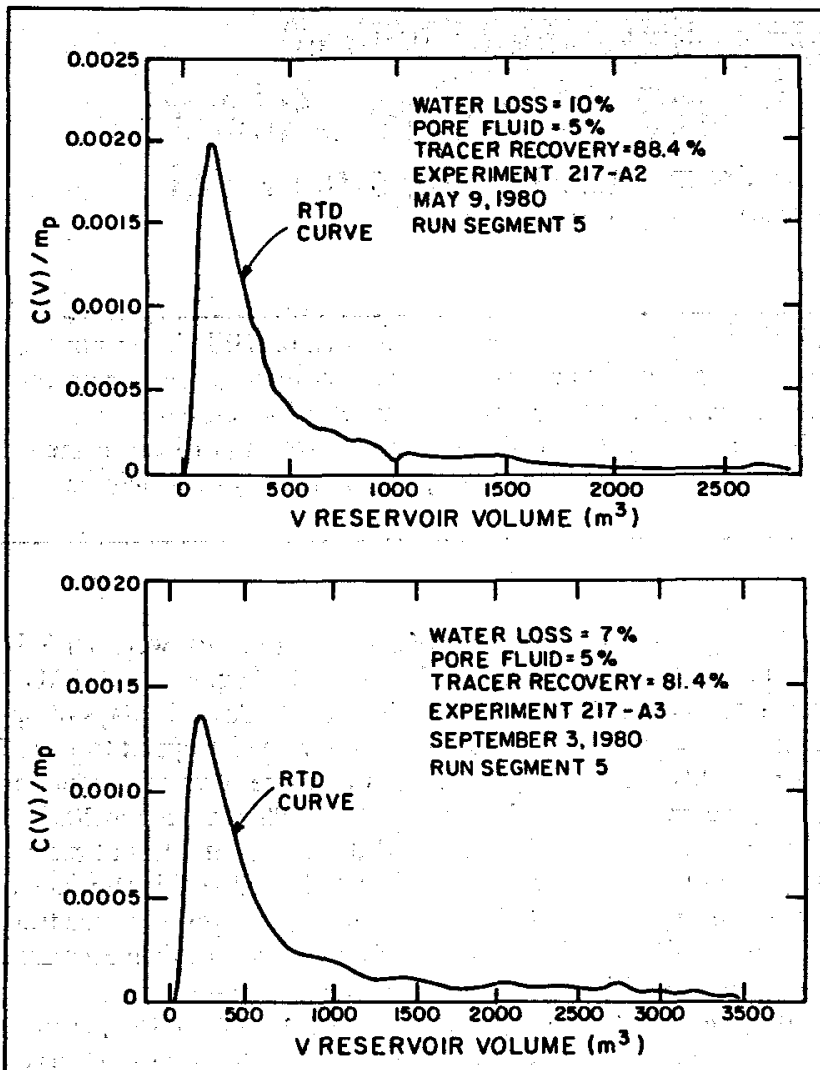

Fig. 1-Bre2 tracer-determined RTD or breakthrough curves for the Phase I reservolr at Fenton Hill. Operating conditions and reservolr parameters for each test are listed in Table 10.5 of Ref. 4.

Other heat-transfer models have been proposed for fractured HDR systems to account for these complexities. One such model ${ }^{6}$ treats the reservoir as a composite of several zones of highly fractured rock that behave as a porous continuum.

Tracer Techniques. Throughout the testing periods, tracer pulses were injected into the system and monitored in the produced fluid. Both sodium fluorescein dye and neutron-activated ammonium bromide $\left[\mathrm{NH}_{3} \mathrm{Br}\left(\mathrm{Br}^{82}\right)\right]$ tracers were used to map the flow and mixing patterns in the reservoirs. As described in earlier papers, 7,8 tracer tests provide a direct measure of accessible volume and dispersion levels within the active reservoir. The tracer-concentration history in the production well describes a breakthrough curve giving the distribution of fluid residence times within the reservoir. Changes in reservoir mean volume, $\langle V\rangle$, or modal volume, $\vec{V}$, can be obtained easily from a pulse tracer test. $V$ is simply the volume of fluid produced between the time the tracer pulse was injected into the reservoir and the time the peak tracer concentration appears in the production well. Because the flow channels directly connecting the two wells are apt to have the shortest residence times, 8 represents the fluid volume of the high-permeability paths. $\langle V\rangle$ is calculated by integration over the entire distribution of residence times as

$$
\langle V\rangle=\int_{0}^{\infty} V f(V) \mathrm{d} V
$$

where

$V=$ produced-fluid volume,

$f(V)=C(V) / m_{p}=$ residence-time distribution (RTD), and

$m_{p}=$ mass of tracer injected.

The RTD or breakthrough curve is the normalized tracer response whose integral equals unity at complete recovery of tracer at long times. The integral in Eq. 1 is evaluated by extrapolating the

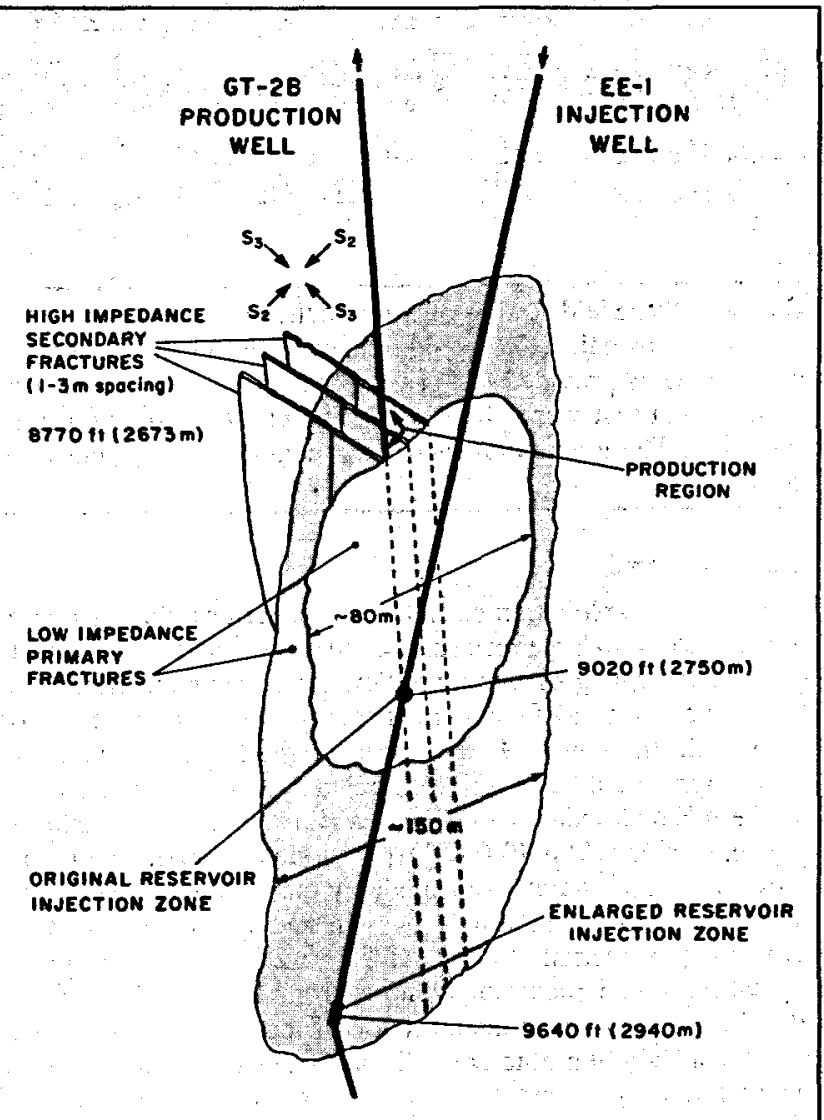

Fig. 2-Inferred system geometry of primary flow paths in the Wells EE-1/GT-2B reservolr (from Ref. 8).

response curve to infinity with an exponential decay, $C(V)$, subject to the restraint that the tracer is completely recovered at an infinite produced volume $(V=\infty)$, after accounting for water loss. The physical significance of $\langle V\rangle$ is that it represents the total volume of all flow paths conducting fluid, regardless of flow velocity.

Geochemical Monitoring. The water circulated in the system is diluted with relatively pure makeup fluid containing only 200 to $300 \mathrm{ppm}$ total dissolved solids (TDS) compared with the steadystate level of approximately 2,500 ppm TDS observed in the produced fluid. The concentrations of specific components in the fluid were monitored throughout the tests to identify dynamic changes in an effort to understand important source and depletion mechanisms controlling the chemistry of the system. Dissolved silica $\left(\mathrm{SiO}_{2}\right)$, sodium $\left(\mathrm{Na}^{+}\right)$, potassium $\left(\mathrm{K}^{+}\right)$, lithium $\left(\mathrm{Li}^{+}\right)$, boron $(\mathrm{B})$, bicarbonate/carbonate $\left(\mathrm{HCO}_{3}^{-} / \mathrm{CO}_{3}^{-2}\right)$, chloride $\left(\mathrm{Cl}^{-}\right)$, fluoride $\left(\mathrm{F}^{-}\right)$, and sulfate $\left(\mathrm{SO}_{4}^{-2}\right)$ were the major species monitored along with radon $(\mathbf{R n})$ and various isotopic ratios. $3,9,10$

Passive Microseismic Measurement Techniques. Both surface and downhole seismometer arrays were used during all segments and SUE both to evaluate potential seismic risks and to map microseismic event structures to infer reservoir geometry. Microseismic source mechanism theories suggest that pressurization of the reservoir with injected fluid will result in either tensile or shear failure, depending on the alignment of the in-situ horizontal principal stresses with the joint structure and on the magnitude of the anisotropy between the two principal horizontal stresses. Thus, by examining the spatial and temporal distribution of events, one can develop reservoir geometry models. Passive microseismic monitoring focuses on mapping events induced by pressurization during fracturing, heat extraction, and overpressurization, such as during SUE. 2,5,11 The uncertainty inherent in locating microseismic events with single-station downhole measurements and hodographic deconvolution techniques must be kept in mind when event maps are interpreted. 


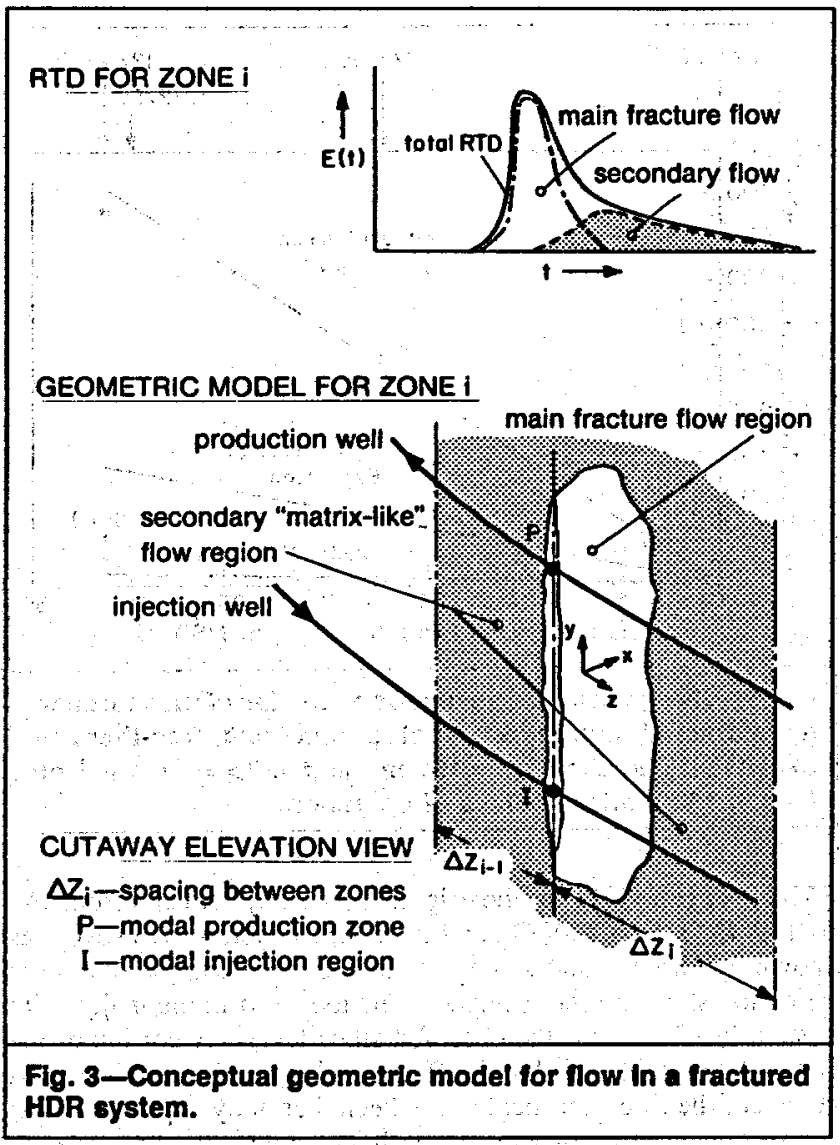

\section{Structural Model of the Fenton HIII Reservolr}

The observed levels of fluid mixing and dispersion illustrated in the tracer-determined RTD's of Fig. 1 are too large to be attributed to single-fracture flow? Furthermore, downhole temperature/: spinner and gamma logging during radioactive tracer measurements using $\mathrm{Br}^{82}$ verified the existence of three major production zones, each with comparable levels of dispersion contributing to the composite RTD. Borehole televiewers and spectral gamma logs consistently indicated the location of these zones.

Hydraulic pressurization to levels just slightly above the least principal horizontal confining stress, $\sigma_{3}$, opens high-injectivity fractures that run approximately vertically from Injection Well EE-1 to Production Well GT-2B. Two sets of nearly orthogonal joints apparently exist: a primary set aligned perpendicular to $\sigma_{3}$ and a secondary set aligned perpendicular to $\sigma_{2} \cdot \mathrm{Br}^{82}$ and temperature logs demonstrated that at least nine fractures containing fluid intersect Wells GT-2B and EE-1. The geophysical and flow data suggest that the major production and injection zones occur near the intersection of a series of parallel secondary fractures with the wellbore. These secondary fractures permit lateral communication of fluid between the primary vertical joints, resulting in macroscopic mixing between intersecting primary and secondary joints. This mixing leads to the high level of fluid dispersion observed in each" production zone. ${ }^{7}$ Fig. 2 depicts a simplified conceptual geometric model of the EE-1/GT-2B reservoir.

The interconnected joint set of Fig. 2 creates a low-impedance, direct connection between Wells EE-1 and GT-2B that is characterized by the short-residence-time portion of the RTD (see Fig. 3). The tail of the distribution can be attributed largely to flow in high-impedance, secondary flow in a matrix-like path of long residence time. This secondary flow path probably samples the reservoir's smaller-scale porosity at larger distances from the interconnected primary joint set. The heat-exchange mechanism for each region is also likely to be different. In the primary path, the dominant heat-removal mechanism would be areal sweep with 2D fluid convection within each major fracture linked to 1D conduction through the rock contained between fractures. In the secondary path, heat is removed by a fluid-displacement mechanism undergoing $3 \mathrm{D}$ volumetric sweep through a porous continuum.

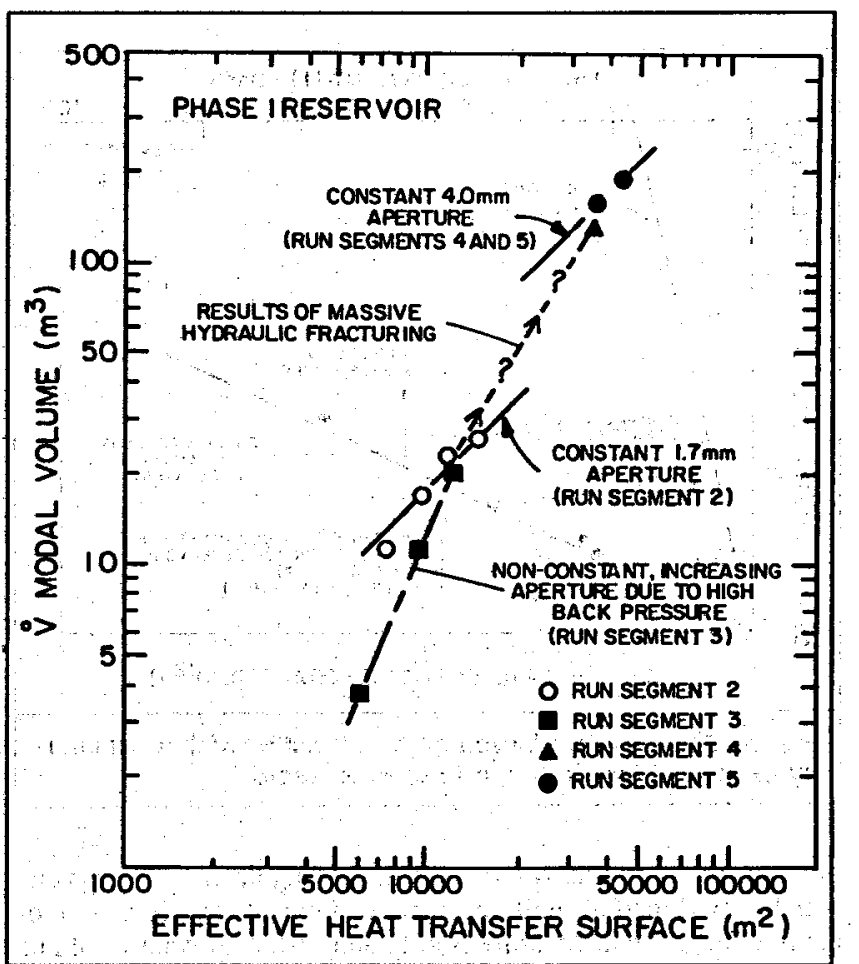

Fig. 4-Emplrical correlation of tracer-determined $\boldsymbol{V}$ and effective heat-transfer surface area. Points shown for Run Segment 5 (solld circles) correspond to modal volumes from Fig. 1.

The $V$ of the reservoir can be regarded as a measure of the void volume of the direct fracture connections. Heat is mined from this portion of the reservoir by convecting fluid over the fracture face, removing thermal-energy from the rock by transient conduction. Thus, a correlation between $\bar{\gamma}$ and the reservoir heat-transfer area might be anticipated. As Fig. 4 shows, such a correlation does exist for the Fenton Hill reservoir and is consistent with data from the British HDR system at Rosemanowes. 4,?

\section{Fleld Evidence of Reservolr Growth}

Data from the heat-extraction tests of the Fenton Hill HDR reservoir will be presented and analyzed separately for (1) tracer measurements of flow distribution and system size, (2) geochemical measurements obtained under recirculation conditions, and (3) microseismic measurements made during SUE.

Tracer-Based Evidence. A complete review of the tracer-test data from Segments 2 through 5 revealed pertinent information regarding the growth of the reservoir caused by heat-extraction and pressurization effects. If crack propagation induced by thermal stress is disregarded, reservoir growth caused by heat extraction conceivably can be ascribed to a thermal contraction effect. As the rock surrounding the fracture shrinks, fracture apertures increase, causing an increase in tracer-measured reservoir volumes. In addition, the interpretation of tracer volume changes could be used to develop improved methods of reservoir operation-e.g., remedial pressurization for stress relief, such as SUE, or a huff ' $n$ ' puff operation mode, in contrast to our normal (stress-constrained) continuous mode of extracting heat.

Fig. 5 plots modal volume increase, $\Delta \dot{V}$, as a function of net thermal energy extracted from the reservoir, $\Delta E_{h}$, excluding any energy contributions from the wellbores. Essentially identical linear behavior is observed for the low-backpressure experiment, Segment 2, of the original reservoir and the low-backpressure experiment, Segment 5, of the enlarged system. In spite of the nonlinear coupled effects of thermal contraction, pore and fracture inflation caused by sustained pressurization, and local irreversibilities resulting in fracture propagation, a simple correlation between $\Delta V$ and $\Delta E_{h}$ exists. Furthermore, this simple relationship persists even in the 


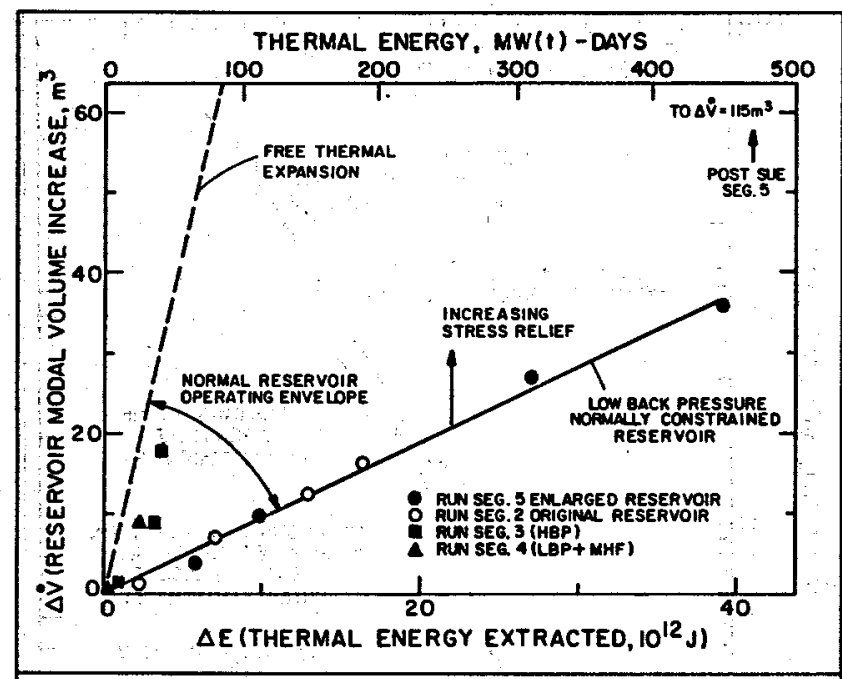

Fig. 5-Change in modal volume as a function of thermal energy extracted for all Phase I reservoir tests.

presence of the confining stresses surrounding the active reservoir, which would tend to limit unconstrained expansion. The slope of the line for low backpressure is only about $10 \%$ of what would be expected for free thermal expansion $\left\{\Delta V=\left[\beta_{v} /(\rho C)_{r}\right] \Delta E_{h}\right\}$ in a stress-free environment. Values of $\beta_{y}=24 \times 10^{-6} \mathrm{~K}^{-1}[13.3 \times$ $\left.10^{-6} \circ \mathrm{R}^{-1}\right], C_{r}=1000 \mathrm{~J} /(\mathrm{kg} \cdot \mathrm{K})\left[0.24 \mathrm{Btu} /\left(\mathrm{lbm}-{ }^{\circ} \mathrm{F}\right)\right]$ and $\rho_{r}=$ $2700 \mathrm{~kg} / \mathrm{m}^{3}\left[168.6 \mathrm{lbm} / \mathrm{ft}^{3}\right]$ were used to represent the granite matrix.

Ideally, the region between the low-pressure data and the freethermal-volume lines would define an envelope of reservoir operating conditions for the major joints. As stresses are relieved, for example during SUE or the high-backpressure test of the original reservoir (Segment 3), the reservoir, in theory, moves away from its normally constrained condition toward the free-thermal-expansion line. In practice, however, the situation is apparently more complex. The modal and mean volume increases that occurred during the Segment 5 test as a result of energy extraction are plotted on Fig. 6 along with the calculated free-thermal-expansion line. $V$ is taken to represent the volume of the primary joint system, while $\langle V\rangle$ is assumed to correspond to the total accessible reservoir volume, including the secondary system. The large increase in $\langle V\rangle$ above the free-thermal-expansion line suggests that the opening of preexisting joints must have been occurring along with thermal contraction. Thus, thermal stresses apparently have induced additional secondary crack growth. Most of the measured reservoir volume growth occurred in the high-impedance secondary path that is characterized by the tail of the RTD. The propensity of fluid to channel through a few low-impedance joints was dominant throughout the heat-extraction test, although the shift of larger percentages of the injected fluid to secondary flow paths is evident from the systematic decline in tracer recovery during Segment 5. A simple water mass balance provides a feasible explanation for the large increase in $\langle V\rangle$. About $15000 \mathrm{~m}^{3}\left[529,700 \mathrm{ft}^{3}\right]$ of water was lost to the underground formation during the 286 days of Segment 5 . This fluid is ordinarily described as water loss, an irreversible permeation loss of fluid to the surrounding rock. If, instead of water loss, a fraction of this fluid (about 13\%) created new fluid flow paths connecting the two wells, then the mean volume increase of $2000 \mathrm{~m}^{3}[70,630$ $\mathrm{ft}^{3} \mathrm{l}$ is explained.

Geochemical Evidence. Geochemical monitoring during recirculation tests at Fenton Hill indicated that the displacement of in-situ pore fluids provided a source for observed levels of dissolved $\mathrm{Cl}$, $\mathrm{B}, \mathrm{Na}, \mathrm{K}$, and $\mathrm{Li} .{ }^{12}$ Furthermore, quartz and $\mathrm{Na} / \mathrm{K} / \mathrm{Ca}$ geothermometry estimates of reservoir temperatures remain relatively constant at 185 to $190^{\circ} \mathrm{C}$ [ 365 to $374^{\circ} \mathrm{F}$ ] for quartz and 190 to $200^{\circ} \mathrm{C}$ [374 to $392^{\circ} \mathrm{F}$ ] for $\mathrm{Na} / \mathrm{K} / \mathrm{Ca}$ throughout the heat-extraction tests. In contrast, the produced-fluid temperatures declined from 175 to

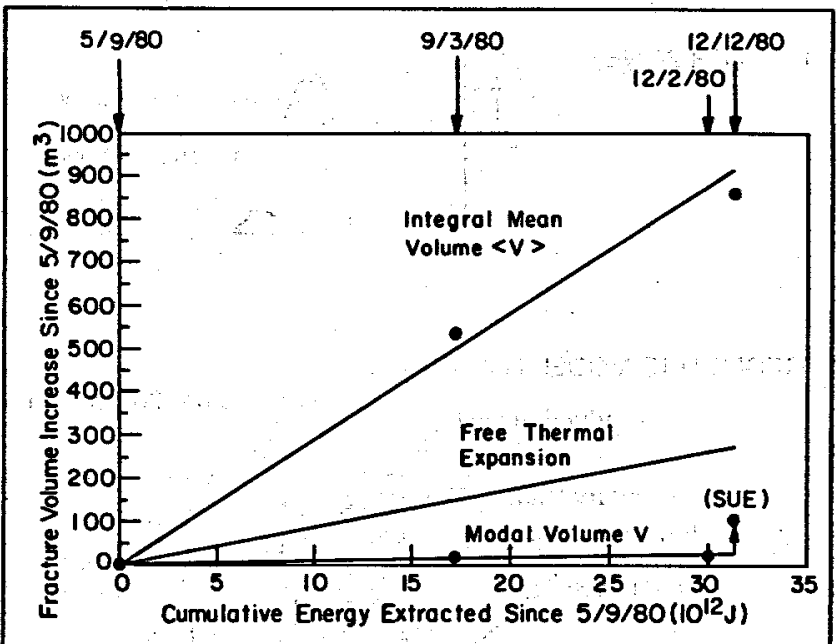

Fig. 6-Change in modal volume as a function of thermal energy extracted during Segment 5 test with free-thermalexpansion line shown. $V=161 \mathrm{~m}^{3}$ and $\langle V\rangle=1311 \mathrm{~m}^{3}$ on May 9,1980 , after 61 days of operation:

$85^{\circ} \mathrm{C}$ [347 to $185^{\circ} \mathrm{F}$ ] for the original Phase I system and from 158 to $149^{\circ} \mathrm{C}$ [ 316 to $300^{\circ} \mathrm{F}$ ] for the enlarged system. However, as shown by Grigsby and Tester, ${ }^{10}$ the rate of quartz dissolution is much too slow and the residence time too short in the major joint system to account for the observed silica levels. A portion of the recirculated fluid must have sufficiently long residence times in a region of the reservoir that has not been thermally depleted so that the silica concentration can approach its quartz-saturation value at the initial rock temperatures of about 185 to $195^{\circ} \mathrm{C}$ [ 365 to $383^{\circ} \mathrm{F}$ ]. This portion of fluid is then mixed with fluid from the shortresidence-time paths in the cooler regions of the reservoir.

The geochemical observations provide corroborating evidence of a secondary, long-residence-time flow path that is consistent with the tracer data. By assuming a pore-fluid displacement mechanism for certain species, estimates of the fraction of flow in the primary and secondary paths can be made (see Ref. 10 for details). For example, if the secondary path produces a solution saturated in silica at $190^{\circ} \mathrm{C}\left[374^{\circ} \mathrm{F}\right]$, which assumes rapid dissolution kinetics and a high ratio of exposed rock surface area to circulated fluid volume, then about $30 \%$ of the flow must come from this hot source, with the remaining $70 \%$ from the primary joints. This estimate is further supported by tracer experiments where roughly $70 \%$ of the tracer is recovered in the main peak of the RTD and the remainder in the tail of the distribution.

Microseismic Evidence From Reservoir Stress Release. To study the dynamics of reservoir changes induced by heat extraction, SUE was conducted in Dec. 1980. During this operation, both wellbores were pressurized simultaneously for about 8 hours. At the time of this experiment, $V$ alone was used as a measure of the fracturesystem volume. Notice that $V$ increased only slightly during Segment 5 , much less than would be expected if the rock were contracting freely. Our hypothesis was that thermal stresses were partially "locked in" frictionally and not allowed to relieve themselves by means of a thermal stress-cracking mechanism. Confinement during normal operation results from the large in-situ stresses, ranging from $\sigma_{2}$ to $\sigma_{3}$, that are naturally imposed on the fracture system. Pressurization above $\sigma_{3}$ was applied during SUE to allow the cooled and thermally constrained rock to redistribute stresses more uniformly.

The result of the experiment was a substantial increase in $\stackrel{\nabla}{V}$, as measured in two tracer experiments, one before and one after SUE. The new estimates of $\langle V\rangle$ suggest a slightly different yet still optimistic interpretation of SUE. Note that $\langle V\rangle$ was increasing at a rapid rate throughout Segment 5, even before SUE. Unfortunately, experimental difficulties during Experiment 217-A4 (directly preceding SUE) did not permit measurement of the tail of the RTD; thus making an accurate calculation of $\langle V\rangle$ impos- 


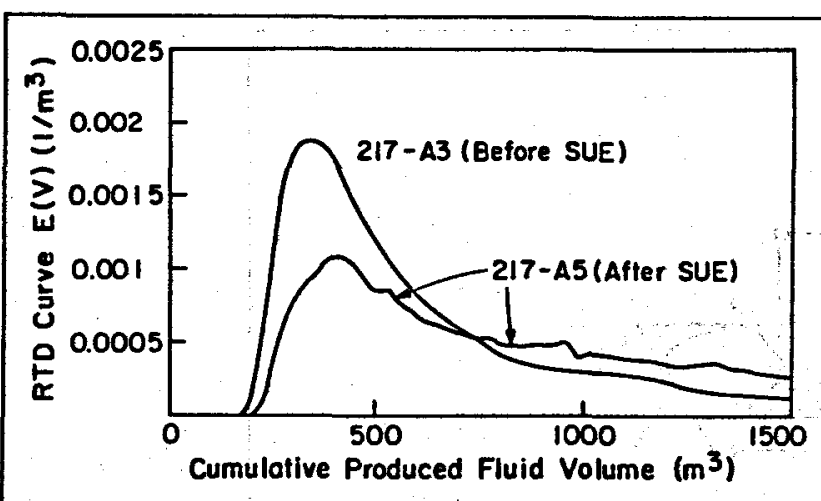

Fig. 7-Comparison of tracer response curves before and after the SUE.

sible. Nonetheless, the dramatic jump in $\hat{V}$ caused by SUE does not seem to have been accompanied by a similar increase in $\langle V\rangle$.

$A$ key observation is that $\langle V\rangle$ was increasing throughout Segment 5 at a higher rate than can be explained by thermal contraction alone. Thermal stress cracking seems to have been occurring throughout the test, but with the new fractures accepting very little flow. This point is discussed in greater depth in the next section. Because $V$ corresponds only to low-impedance connection, it did not increase substantially. These facts suggest that SUE redistributed the primary flow among existing major fractures rather than creating new fracture volume. Fig. 7 compares tracer curves before and after SUE on the same scale. There appears to have been a redistribution of flow to a larger number of fractures, resulting in a larger $V$ and greater tracer spreading.

Microseismic measurements in the Phase I reservoir during hydraulic fracturing and energy-extraction operations have been used to assess induced seismic risks and to specify system geometry. Event maps during the early stages of fracturing to enlarge the active reservoir showed a distinct growth upward and outward from the injection region in Well EE-1 toward the production region in Well GT-2B. ${ }^{3}$ The events were characterized by large compressive and shear components, indicating that both tensile fracturing and shear displacement along joints were occurring throughout the active reservoir. When hodographic techniques are used to deconvolve single-station measurements with a three-axis downhole geophone array, the events observed during the hydraulic stimulation phase of the initial pressurization generally are clustered about a northby-northwest vertical plane $( \pm 20 \mathrm{~m}[ \pm 66 \mathrm{ft}])$ whose strike has remained quite constant. 2,13 Although this planar feature was seismically active in the early period, continued pressurization with water permeation results in a general displacement of events away from the planar structure. During Segment 5, a spherical region of seismic events surrounded the injection/production region at distances $>500 \mathrm{~m}[1,640 \mathrm{ft}]$ from the planar locus of events. The lowimpedance, primary fracture regions of the reservoir that were severely thermally depleted during Segment 5 became aseismic, while the high-impedance secondary zone showed continued seismicity throughout the test. This level of microseismic activity is consistent with the observed increase of $\langle V\rangle$ from the tracer tests. All these data suggest that even though the reservoir is growing, the enlarged region is not being exploited fully for energy removal, given the present wellbore geometry.

Fig. 8 shows a model of this concept, where the vertical dimensions of two aseismic planar-event zones extending from about 2820 to $2950 \mathrm{~m}[9,250$ to $9,680 \mathrm{ft}]$ and from about 2650 to $2750 \mathrm{~m}[8,690$ to $9,020 \mathrm{ft}$ coincide with the location of the thermally depleted regions depicted on the Well EE-1 temperature log. The lower depleted zone was caused primarily by Segment 5 testing of the enlarged system, whereas the upper zone resulted from Segment 2 testing of the original system.

Pressurization of the reservoir during SUE resulted in significant seismic activity just outside and peripheral to the most active heatexchange regions. Fig. 9 shows plan and elevation maps of events monitored during SUE. The aseismic region centered around Well EE-1 injection zone has an effective diameter of about $100 \mathrm{~m} \mathrm{[330}$

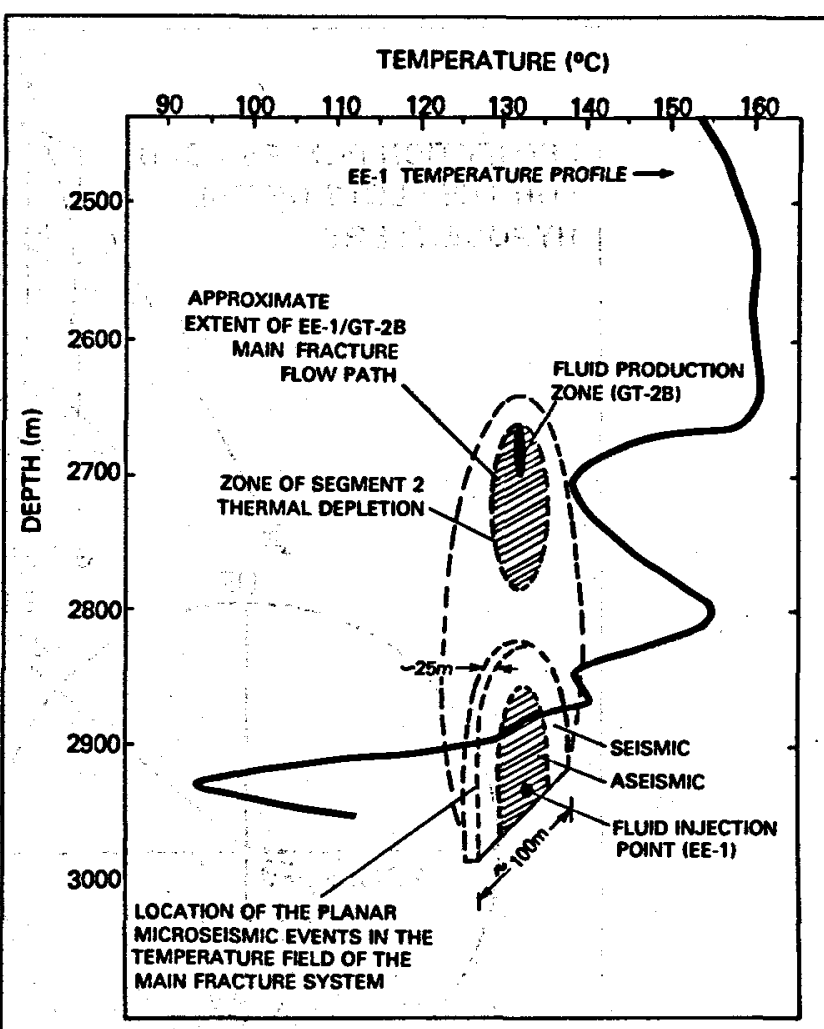

Fig. 8-Temperature survey In Injection Well EE-1 after parthal thermal recovery (July 10, 1981) showing a correlation of the thermally depleted regions with the microselsmic planar-event aseismic regions.

$\mathrm{ft}$, consistent with the size of the thermally depleted fracture area. The high level of thermal contraction resulting from the large temperature change in the injection region apparently has relieved the in-situ stresses to such an extent that subsequent pressurization during SUE produced no further failure and microseismicity. A time-sequence analysis of the event patterns during SUE showed a clustering of microseismic activity in a series of zones that move out from the most active heat-transfer region as the pressure field expands outward (see Refs. 2 and 5 for details).

The SUE test procedure may prove to be not only an effective means of mapping the progress of thermal depletion within an active HDR reservoir but also may suggest a method of enlarging the active reservoir volume and/or improving the connectivity between injection and production wells.

\section{Interpretation of Observed Growth}

One possible interpretation of reservoir growth is provided by heattransfer modeling of the thermal drawdown observed during Segments 2 and 3 with the original system and Segment 5 with the enlarged reservoir. If the areal heat-transfer model we discussed earlier is assumed to represent the reservoir correctly, then the effective heat-transfer area has to be increased as time passes during the production period to fit accurately the thermal-drawdown data for all heat-extraction tests. For a fixed-surface-area fracture system, the predicted temperature decline would be greater than that observed. Both ID convective modeling with multiple interacting fractures and 2D convective modeling with thermally independent fractures showed similar results ${ }^{2}$ : Segment 2 increases from 7500 to $15000 \mathrm{~m}^{2}$ [80,730 to $\left.161,460 \mathrm{ft}^{2}\right]$, Segment 3 from 6000 to $12000 \mathrm{~m}^{2}\left[64,590\right.$ to $\left.129,170 \mathrm{ft}^{2}\right]$, and Segment 5 , from 37000 to $45000 \mathrm{~m}^{2}\left[398,280\right.$ to $484,390 \mathrm{ft}^{2}$ ].

Although this particular interpretation depends on the assumption that an areal-sweep heat-transfer model applies, the observed increase in $V$ and $\langle V\rangle$ may also be correlated to changes in the heatproduction mechanism of the reservoir. For example, if the volumetric heat-transfer model is correct, then the volume increase can be attributed directly to thermal stress cracking or other forms of 


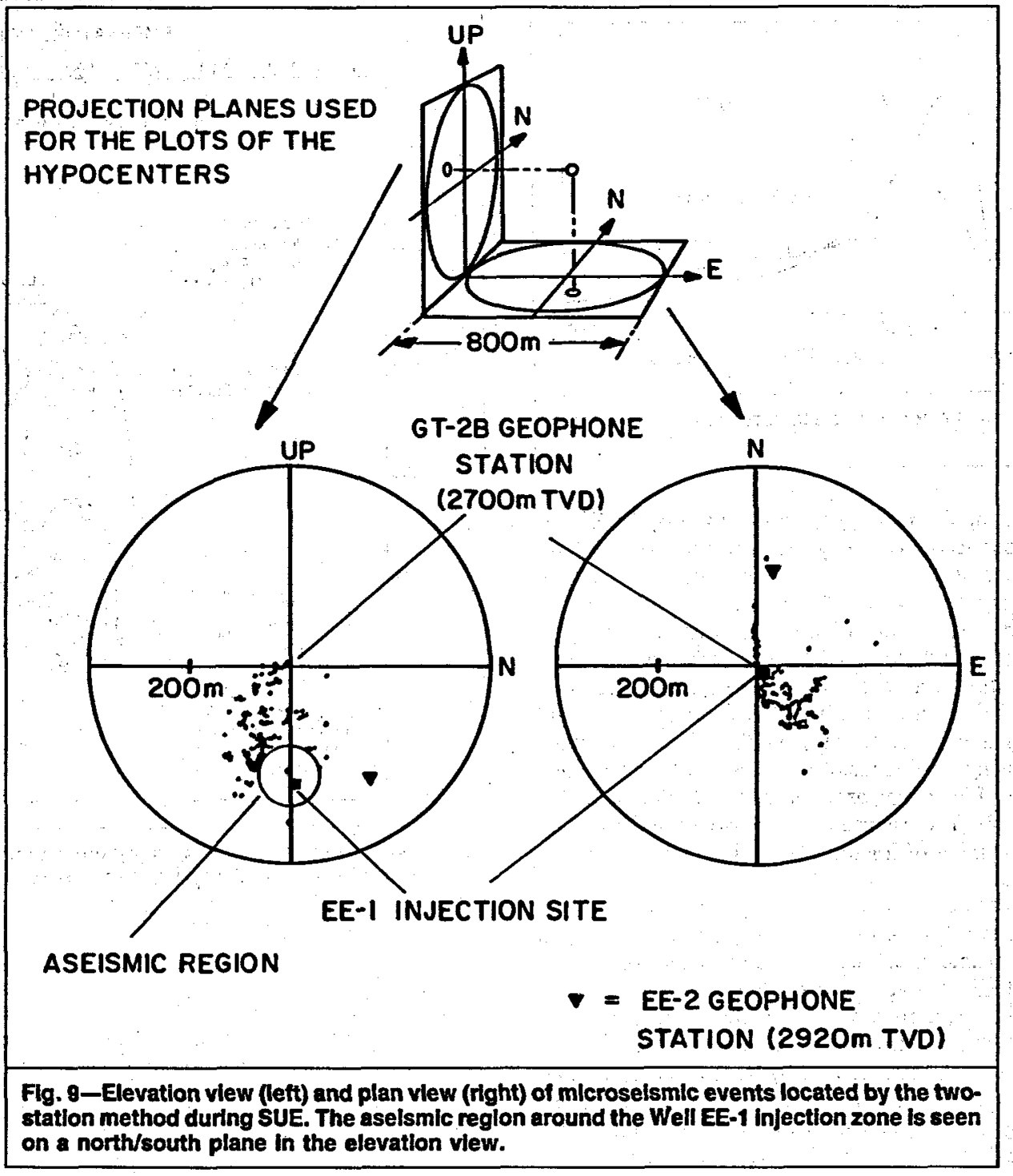

reservoir growth. This would change the details of how fluid flows through portions of the reservoir, such as through more highly fractured rock zones, but because these zones are cooler, this flow redistribution may have little effect on thermal capacity or "actual reservoir size." At this point, it is difficult to determine which heattransfer model is correct.

Our optimistic analysis of reservoir growth attributes the observed increase in the active microseismic region and increase in $V$ and $\langle V\rangle$ to the creation of new fractures penetrating into hot regions of rock that may augment the reservoir's heat-extraction capacity. A more pessimistic explanation is that a thermal-stress-induced redistribution of flow into a thermally depleted rock region increases reservoir volume but not heat-extraction capacity. Thermally induced stress could lead to the propagation of secondary cracks through a process known as thermal stress cracking. A first-order theoretical analysis has been performed to provide a basis for evaluation of this possible mechanism of reservoir growth.

The heat-transfer enhancement that may result from thermal stress cracking will depend on the flow properties of the secondary crack system. If the hydraulic fracture is pressure-propped, then a critical crack aperture value of $b=0.4 \mathrm{~mm}[0.002$ in.] is estimated at the point where flow in the secondary system becomes important (see the Appendix). This condition would also permit some degree of fluid circulation induced by buoyant forces as cold fluid enters a vertical fracture and sinks downward, sweeping outward as it is heated. 5 If the main fracture is self-propped by roughness asperities on the surface of the fracture, then $b$ would be about 0.2 $\mathrm{mm}[0.008 \mathrm{in}$.]. In either case, one would expect to see significant thermal stress enhancement of heat transfer within a few months of operation. Furthermore, as fluid begins to flow in the larger thermal cracks, conductive heat transfer becomes 2D, which causes even greater thermal contractions, leading to higher flow rates and higher heat-extraction rates.

In considering the potential enhancement by thermal stress cracking to sustain produced-fluid temperature levels, it is essential to identify whether the induced changes in flow distribution actually access undepleted regions of hot rock. The likely initiation sites for thermal cracks will be at zones of maximum stress that have undergone the most cooling, and this would not increase the reservoir's thermal capacity. Harlow and Pracht ${ }^{14}$ and Demuth and Harlow ${ }^{15}$ examined this problem theoretically in some detail. According to their results, one can be cautiously optimistic that augmented heat extraction would occur, but field verification in long-term flow testing has not been demonstrated.

An alternative hypothesis might interpret the volume increase as a simple separation of fracture faces or an increase in aperture as a result of thermal contraction. This alternative hypothesis is also pessimistic because it says that, over time, a short-circuiting fracture (or fractures) would transmit more and more flow. This type of "runaway" fracture would undoubtedly cool down very rapidly because most of the flow would sweep across a small surface area. The consequence would be premature thermal drawdown.

Because $\dot{V}$ and $\langle V\rangle$ are simple fracture volume measurements, they cannot be used alone to distinguish between the thermalstress-cracking and fracture-face-separation mechanisms. Individual fracture-zone RTD's suggest strongly that the fracture volume growth appears to be accompanied by a more uniform (volumetriclike) flow through more fractures, as opposed to a more channeled 
flow through short-circuiting paths. Individual tracer-response curves from various exit regions show that the permeability between fracture zones increased steadily during Segment 5 to the point where, at the end of the experiment, two fracture zones that were initially independent appear to have merged into a single zone. ${ }^{7}$ Also, flow fraction measurements in Well GT-2B remained constant throughout the experiment, refuting the idea that the joint of lowest flow impedance will accept most of the injected fluid over time.

\section{Conclusions}

By any criteria, the prototype HDR reservoir at Fenton Hill grew in size as heat was extracted. The combined set of tracer, geochemical, microseismic, and thermal/hydraulic data suggest that this growth may have augmented the heat-production capacity, and thus the thermal lifetime, of the reservoir. Considerable evidence exists to support the hypothesis that fracture extension induced by thermal stresses and/or sustained hydraulic pressurization was the primary growth mechanism. It is very likely that this type of phenomenon would be observed in hydrothermal and oil and gas reservoirs whenever in-situ stresses were modified substantially by induced thermal stress after long-term injection of fluids at temperatures different from those of the surrounding formation.

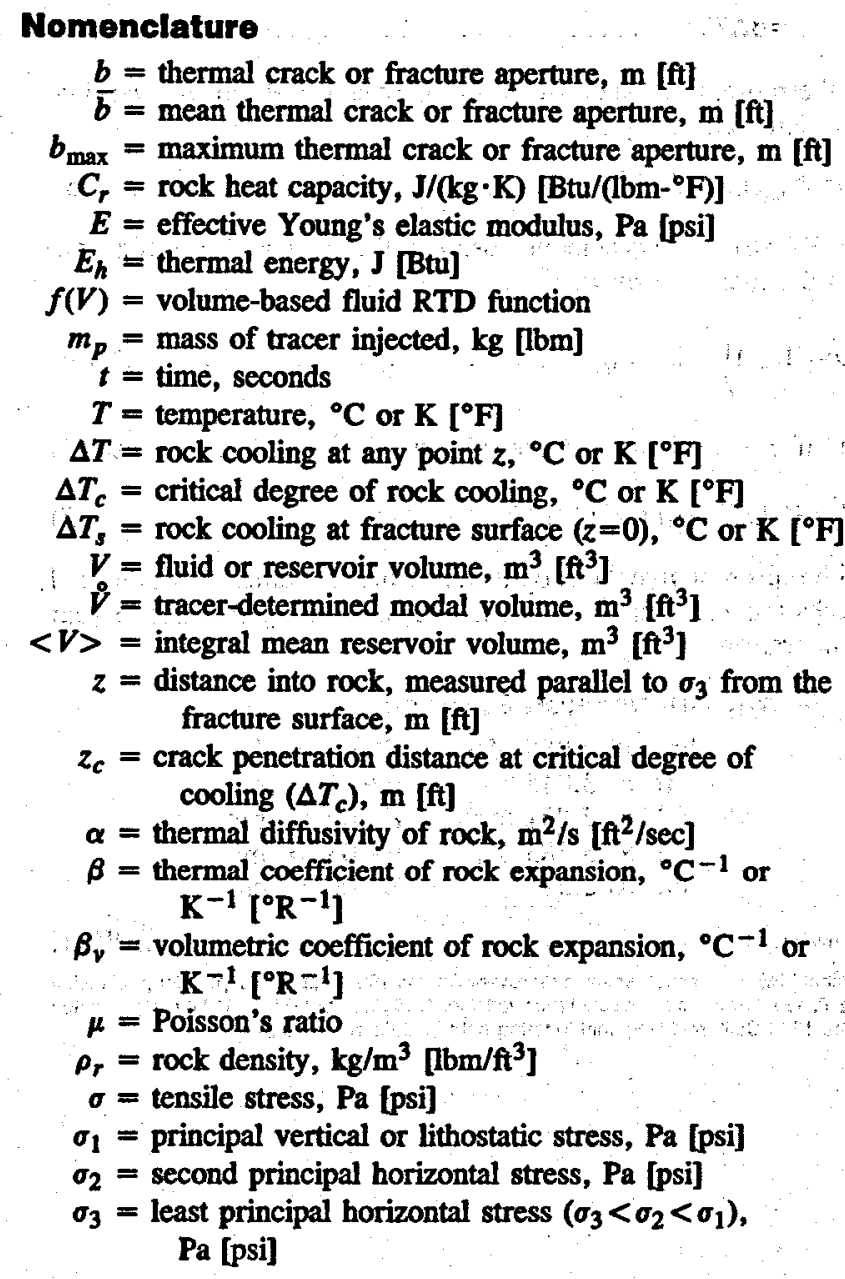

\section{Acknowiedgments}

We acknowledge the support provided by the HDR project team at the Los Alamos Natl. Laboratory. We are particularly grateful to H. Fisher, L. Aamodt, M. Fehler, J. Albright, G. Zyvoloski, R. Bivins, Z. Dash, and D. Brown for their technical contributions and advice and to L. MacDonald and S. O'Malley for their help in the preparation of the manuscript. Major funding for this project was provided by the U.S. DOE.

\section{References}

1. Murphy, H.D. et al.: "Energy Extraction from Fractured Geothermal Reservoirs in Low-Permeability Crystalline Granite," J. Geophys. Res. (1981) 86, 7145-58.
2. Dash, Z.V. et al.: "Hot Dry Rock Geothermal Reservoir.Testing: 1978 to 1980," J. Volcanology and Geothermal Res. (1981) 15, 59-99.

3. "Evaluation of the Second Hot Dry Rock Geothermal Energy Reservoir: Results of Phase I, Run Segment 5," G.A. Zyvoloski (ed.), Report LA-8940-FiDR, Los Alamos Natl. Laboratory, Los Alamos, NM (1981).

4. Armstead, H.C.H. and Tester, J.W.: Heat Mining, E.F. Spon Ltd., London (1987) Chaps. 9 and 10, 161-318.

5. "Relaxation of Geothermal Reservoir Stresses Induced by Heat Production," H.D. Murphy et al. (ed.), Report LA-8954-MS, Los Alamos Natl, Laboratory, Los Alamos, NM (Aug. 1981).

6. Robinson, B.A. and Jones, G.F.: "A Tracer-Based Model for Heat Transfer in a Hot Dry Rock Reservoir," Proc., Geothermal Resources Council 1987 Annual Meeting, Sparks, NV (Oct. 11-14, 1987).

7. Robinson, B.A., Tester, J.W., and Brown, L.: "Reservoir Sizing Using Inert and Chemically Reacting Tracers," SPEFE (March 1988) 227-34.

8. Tester, J.W., Bivins, R.L., and Potter, R.M.: "Interwell Tracer Analyses of a Hydraulically Fractured Granitic Geothermal Reservoir," SPEJ (1982) 537-48.

9. Grigsby, C.0. et al.: "Rock-Water Interactions in Hot Dry Rock Geothermal System-I. Fluid Mixing and Geothermometry," available from authors, Los Alamos Natl. Laboratory, Los Alamos, NM, to appear in Geothermics (1989).

10. Grigsby, C.O. and Tester, J.W.: "Rock-Water Interactions in Hot Dry Rock Geothermal Systems-II. Modeling Geochemical Behavior," available from authors, Los Alamos Natl. Laboratory, Los Alamos, NM, to appear in Geothermics (1989).

11. Aki, K. et al.: "Interpretation of Seismic Data from Hydraulic Fracturing Experiments at the Fenton Hill, New Mexico, Hot Dry Rock Geothermal Site," J. Geophys. Res. (1982) 87, (B2), 936-44.

12. Grigsby, C.O. et al.: "Rock-Water Interactions in Hot Dry Rock Geothermal Systems: Field Investigations of In Situ Geochemical Behavior," J. Volcanology and Geothermal Res. (1981) 15, 101-36.

13. Albright, J.N. and Pearson, C.F.: "Acoustic Emission as a Tool for Hydraulic Fracture Location," SPEJ (Aug. 1982) 523-30.

14. Harlow, F.H. and Pracht, W.E.: "A Theoretical Study of Geothermal Energy Extraction;" J. Geophys. Res. (1972) 77, 7038-48.

15. Demuth, R.B. and Harlow, F.H.: "Thermal Fracture Effects in Geothermal Energy Extraction," Report LA-7963, Los Alamos Natl. Laboratory, Los Alamos, NM (1979).

\section{Appendix-Thermal-Stress-Cracking \\ Calculations}

The objective here is to estimate the magnitude of the thermal stress effects on fracture propagation. We have assumed that the reservoir was ideally formed by hydraulic fracturing in competent, impermeable granitic rock. For simplicity, we also assumed that the reservoir initially consisted of a single vertically oriented hydraulic fracture. However, the following results are also appropriate for multiple parallel fractures, as long as these are spaced far enough apart (tens of meters) that there is minimal thermal interaction. The hydraulic fracture or fractures extend horizontally in the direction of $\sigma_{2}$, the maximum horizontal compressive earth stress. Thus, heat initially flows conductively from the surrounding rock in the direction orthogonal to $\sigma_{2}$-i.e., coplanar with $\sigma_{3}$, the minimum horizontal compressive earth stress. The thermal gradients set up in the rock by this heat-extraction process result in thermal stresses in the $\sigma_{2}$ direction that eventually could produce thermal cracks that propagate in the $\sigma_{3}$ direction.

The plane-strain solution for the $\sigma_{2}$-direction thermal stress induced in a homogeneous, linearly elastic rock mass that is contiguous to a large hydraulic fracture gives the tensile stress, $\sigma$, as

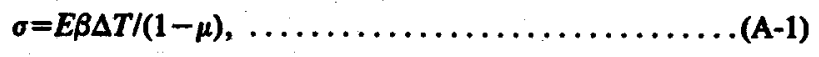

where

$$
\begin{aligned}
E & =\text { elastic modulus, } \\
\beta & =\text { linear thermal-expansion coefficient, } \\
\Delta T & =\text { cooling of rock, and } \\
\mu & =\text { Poisson's ratio. }
\end{aligned}
$$

Assuming that the stress concentration at the crack tip is very large, or that the rock's tensile strength is negligible, cracking will occur when the induced tension just equals $\sigma_{2}$. For numerical examples, data appropriate for the Fenton Hill site have been used. From flow experiments, it has been estimated that $\sigma_{2}=38.6 \mathrm{MPa}[5,600 \mathrm{psi}]$. Values for $E, \beta$, and $\mu$ for granite were taken as $50 \times 10^{3} \mathrm{MPa}$ $\left[7 \times 10^{6} \mathrm{psi}\right], 8 \times 10^{-6} \mathrm{~K}^{-1}\left[4.4 \times 10^{-6}{ }^{\circ} \mathrm{R}^{-1}\right]$, and 0.22 , respec- 


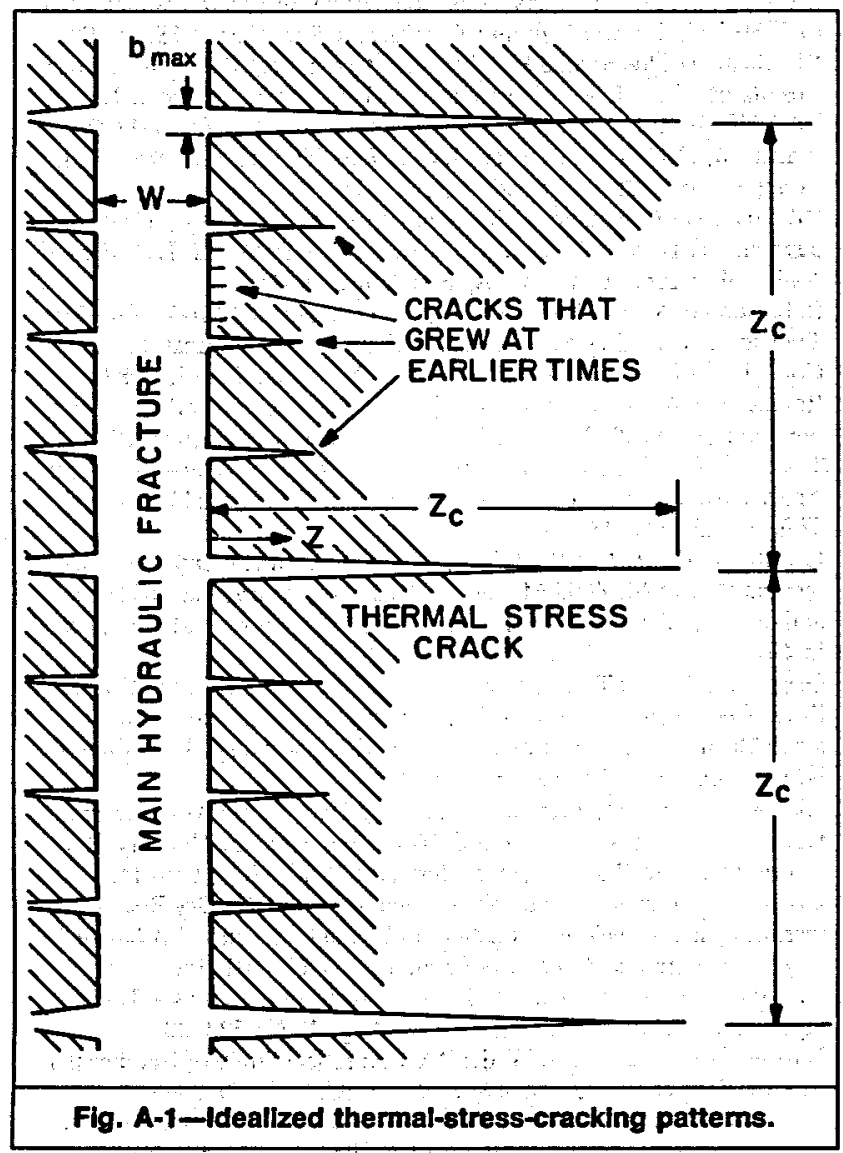

tively. Thus, according to Eq. A-1, cracking is expected when the rock is cooled by about $75^{\circ} \mathrm{C}\left[135^{\circ} \mathrm{F}\right]$. When the rock surface next to the main hydraulic fracture is cooled in excess of $75^{\circ} \mathrm{C}\left[135^{\circ} \mathrm{F}\right]$, the crack penetrates and stays open to the point where the rock temperature is $75^{\circ} \mathrm{C}\left[135^{\circ} \mathrm{F}\right]$ lower than its original temperature.

An estimate of the rock cooling can be obtained by solving the 1D transient conduction problem with a fixed surface-temperature boundary:

$$
\Delta T=\Delta T_{s} \operatorname{erfc}(z / \sqrt{4 \alpha t}),
$$

where

$\Delta T=$ rock cooling at any point,

$\Delta T_{s}=$ rock cooling at surface $(z=0)$,

$z=$ distance into rock, measured parallel to $\sigma_{3}$, from fracture surface,

$\alpha=$ thermal diffusivity of rock, and

$t=$ time.
At the critical degree of cooling $\left(\Delta T_{c}=75^{\circ} \mathrm{C}\left[135^{\circ} \mathrm{F}\right]\right)$, the crack penetration distance, $z_{c}$, becomes

$$
z_{c}=\sqrt{4 \alpha t}\left[\operatorname{erfc}^{-1}\left(\Delta T_{c} / \Delta T_{s}\right)\right] \text {. }
$$

Maximum crack penetration occurs at the maximum $\Delta T_{s}$, which is estimated to be $135^{\circ} \mathrm{C}\left[275^{\circ} \mathrm{F}\right]$ for heat-extraction experiments at Fenton Hill. No cracking at all occurs when $\Delta T_{s}<T_{c}=75^{\circ} \mathrm{C}$ [135 $\mathrm{F}$ ]. If a value of $1.0 \times 10^{-6} \mathrm{~m}^{2} / \mathrm{s}\left[11 \times 10^{-6} \mathrm{ft}^{2} / \mathrm{sec}\right]$ is used for $\alpha$, most thermal cracks penetrated no more than 2 to $3 \mathrm{~m}[6.6$ to $9.8 \mathrm{ft}$ ] for the first $1 / 2$ year of operation.

Having estimated the penetration of these cracks, we next must estimate the spacing of the cracks. This is a typical end-effects problem, for which it is known that, as a first approximation, crack spacings and penetrations are roughly equal. This claim is supported by both calculations and observation of thermal-stress-cracking experiments performed on concrete slabs. Note that this suggests that at early times, the cracks in a reservoir will be closely spaced and of very shallow penetration, but as time goes on, fewer but deeper penetration cracks will form; as Fig. A-1 shows. This process relieves the stress field around the shallow cracks.

If the aperture of the small stress-relieved cracks is ignored, then the maximum aperture, $b_{\max }$, of the largest cracks at any time is

$$
b_{\max }=\beta \Delta T_{s} z_{c} \text {. }
$$

Furthermore, if the aperture is approximated as elliptically varying with penetration depth,

$$
b=b_{\max }\left(1-z / z_{c}\right)^{2} \text {. }
$$

Eq. A-6 also ensures smooth closure of the crack at its tip. If $z=z_{c}$, then the mean aperture, $\bar{b}$, is

$$
\bar{b}=\left(1 / z_{c}\right) \int_{0}^{z_{c}} \mathrm{~d} z=b_{\max } / 3 \text {. }
$$

And if Eqs. A-5 and A-4 are substituted in Eq. A-6, the result is

$$
\bar{b}=2 / 3 \beta \Delta T_{s} \sqrt{\alpha t}\left[\operatorname{erfc}^{-1}\left(\Delta T_{c} / \Delta T_{s}\right)\right] \text {. }
$$

With representative thermophysical property values, most thermal cracks are $<1 \mathrm{~mm}$ [0.04 in.] in aperture during the first $1 / 2$ year of operation.

\section{SI Metric Conversion Factors}

$$
\begin{array}{rl}
\text { Btu } \times 1.055056 & \mathrm{E}+00=\mathrm{J} \\
\mathrm{ft} \times 3.048^{*} & \mathrm{E}-01=\mathrm{m} \\
\mathrm{ft}^{3} \times 2.831685 & \mathrm{E}-02=\mathrm{m}^{3} \\
\text { gal } \times 3.785412 & \mathrm{E}-03=\mathrm{m}^{3} \\
\text { in. } \times 2.54^{*} & \mathrm{E}+00=\mathrm{cm}
\end{array}
$$

"Conversion factor is exact.

Original SPE manuscript recelved for revlew April 2, 1986. Paper accepted for publication Aug. 8, 1988. Revised manuscript recelved Jan. 4, 1988. Paper (SPE 15124) first presented at the 1986 Callfornia Regional Meeting held in Oakland, Aprit 2-4. 